\title{
Plasma B-type Natriuretic Peptide Levels in Stable Heart Failure Patients
}

\author{
A Khadeja $\mathrm{Bi}^{1}, \mathrm{R}$ Chitraa $^{2}$, S Suganya ${ }^{3}$
}

\begin{abstract}
Introduction: Heart failure (HF) is a major and growing public health problem among the global population. Cardiac biomarkers are a promising tool for the early and specific detection of heart failure. B-type natriuretic peptide (BNP) is one such cardiac biomarker released in response to ventricular myocyte stretch.

Aim: The aim of the present study was to estimate the levels of plasma BNP in patients with stable chronic heart failure (CHF) and to compare them with controls. Further to correlate the relationship between plasma BNP levels and factors like age, gender and left ventricular ejection fraction (LVEF), in the two groups.

Materials and methods: A case-control study conducted in Rajiv Gandhi Government General Hospital, Chennai, Tamil Nadu, India consisting of 55 stable CHF patients on treatment and 35 controls. Serum creatinine was estimated adopting modified Jaffe's method. eGFR was calculated using the modification of diet in renal disease (MDRD) formula. Plasma BNP levels were measured by ELISA.

Results: The mean BNP concentration in patients with stable CHF was $60.46 \pm 16.13 \mathrm{pg} / \mathrm{mL}$, while in controls it was $20.94 \pm 5.81 \mathrm{pg} / \mathrm{mL}$ and the difference was highly significant $(p=0.001)$. As the age increases an increasing trend in the values of plasma BNP was observed in both groups. There was a strong negative linear relationship $(r=-0.798)$ observed between LVEF and BNP levels in the study population. A cut-off level of $30.2 \mathrm{pg} / \mathrm{mL}$ for plasma BNP had a $100 \%$ sensitivity and specificity to predict CHF.

Conclusion: Our study concludes that plasma BNP was significantly higher in patients with stable chronic heart failure than in the controls. Plasma BNP as a biomarker will help in identifying stable CHF patients who are asymptomatic, on their adequacy of treatment.

Keywords: B-type natriuretic peptide, Biomarker, Case-control study, Heart failure.

Indian Journal of Medical Biochemistry (2019): 10.5005/jp-journals-10054-0083
\end{abstract}

\section{INTRODUCTION}

A structural or functional abnormality of the heart, which is longstanding and impairing its ability to pump adequate blood to the peripheral tissues to meet their metabolic demands, results in chronic heart failure (CHF). ${ }^{1}$ Worldwide around 26 million people suffer from HF. ${ }^{2}$ Diverse molecular pathways like an injury to the cardiomyocytes, activation of the neuro-hormones, inflammation, oxidative stress, fibrosis and remodeling of the extracellular matrix are involved in the pathogenesis of $\mathrm{HF}^{3}$ The major cause for symptoms in CHF is the excessive circulating blood volume. In humans, Renin-angiotensin Aldosterone system and Natriuretic peptides act antagonistically and maintain euvolemia.

When the circulating blood volume is increased causing cardiac ventricles to stretch, pro-BNP is cleaved into the active fragment BNP (32 amino acids) and the inactive fragment NT pro-BNP which are released into the blood in equimolar amounts. ${ }^{4}$ BNP acts via NPRA cell surface receptors and raises the intracellular cGMP levels in the effector cells. The physiologic actions of BNP are to promote natriuresis, diuresis and vasodilation. The concentration of BNP in an untreated HF patient can be as high as in thousands. ${ }^{5}$ Precise monitoring of the short-term ventricular stress response together with its stability in HF patients with early renal failure, ${ }^{6}$ makes BNP estimation advantageous over NT-pro-BNP. Periodic assessment of BNP in patients with CHF gives an objective data which provides clues for anticipating cardiac decompensation and facilitating therapeutic adjustment in advance. ${ }^{7}$ The aim of the present study was to estimate the levels of plasma BNP in patients with stable CHF and to compare them with controls. Further to correlate the relationship between plasma BNP levels and factors like age, gender and left ventricular ejection fraction (LVEF), in the two groups.

\footnotetext{
${ }^{1}$ Assistant Professor, ${ }^{2}$ Professor, ${ }^{3}$ Tutor

1,3 Department of Biochemistry, Karpaga Vinayaga Institute of Medical Sciences, Chinna Kolambakkam, Tamil Nadu, India

${ }^{2}$ Institute of Biochemistry, Madras Medical College, Chennai, Tamil Nadu, India
}

Corresponding Author: A Khadeja $\mathrm{Bi}$, Assistant Professor, Department of Biochemistry, Karpaga Vinayaga Institute of Medical Sciences, Chinna Kolambakkam,Tamil Nadu, India, e-mail: akhadbi@gmail.com

How to cite this article: Bi AK, Chitraa R, Suganya S. Plasma B-type Natriuretic Peptide Levels in Stable Heart Failure Patients. Indian J Med Biochem 2019;23(1):189-192.

Source of support: Nil

Conflict of interest: None

\section{Materials AND METHODS}

A case-control investigation on the levels of plasma BNP in stable chronic heart failure patients was carried out between October 2012 and October 2013 in Rajiv Gandhi Government General Hospital, Chennai, Tamil Nadu, India.

\section{Data Collection}

The study was conducted after obtaining Institutional Ethical committee clearance. The study group comprised of 55 known cases of stable CHF patients who attended the review outpatient department of cardiology. There were 39 adult males and 16 females. The control group comprised of 35 adults attending the cardiology outpatient department for cardiac evaluation under anesthetic fitness for surgeries. There were 23 males and 12 females in the control group.

(O) The Author(s). 2019 Open Access This article is distributed under the terms of the Creative Commons Attribution 4.0 International License (https://creativecommons. org/licenses/by-nc/4.0/), which permits unrestricted use, distribution, and non-commercial reproduction in any medium, provided you give appropriate credit to the original author(s) and the source, provide a link to the Creative Commons license, and indicate if changes were made. The Creative Commons Public Domain Dedication waiver (http://creativecommons.org/publicdomain/zero/1.0/) applies to the data made available in this article, unless otherwise stated. 


\section{Inclusion Criteria}

Cases

- Stable CHF patients with Left ventricular ejection fraction $<45 \%$ by echocardiography.

- Patients were on treatment for CHF with Diuretics, $\beta$-blockers, ACE inhibitors and statins.

\section{Controls}

Patients having no symptoms of heart failure with LVEF $\geq 60 \%$ by Echocardiogram.

\section{Exclusion Criteria}

- Newly diagnosed heart failure patients of $<6$ months duration,

- Acute or decompensated heart failure patients,

- Renal failure (eGFR $<90 \mathrm{~mL} / \mathrm{min})$

- Anemia $(\mathrm{Hb}<10 \mathrm{~g} / \mathrm{dL})$,

- Thyroid dysfunction.

\section{Procedure}

Four $\mathrm{mL}$ of blood was collected from the anti-cubital vein of the patients and was aliquoted in EDTA tube and red-capped tube. The samples were centrifuged within 30 minutes of collection and were stored at $-70^{\circ} \mathrm{C}$ until further processing. Plasma and serum samples were used for BNP and creatinine estimations respectively. Serum creatinine was estimated first by modified Jaffe's method, using an IDMS traceable calibrator and eGFR was calculated using the MDRD formula. Patients with eGFR $>90 \mathrm{~mL} /$ $\mathrm{min} / 1.73 \mathrm{~m}^{2}$ were only included in the study as case or control. The plasma B-type Natriuretic Peptide levels were estimated using the Competitive ELISA method (RayBiotech, Inc, USA) using ELISA plate analyzer and ELISA plate washer (Robonik, India).

\section{Results}

All the results obtained were statistically analyzed using SPSS software $17.0 \mathrm{v}$. Mean and the standard deviation was found for all parameters. Chi-square test was used to compare factors like smoking, alcohol intake, the presence of diabetes mellitus and hypertension. The concentration of plasma BNP and LVEF levels in stable CHF patients and controls were compared using independent " $t$ " test. Relationship of plasma BNP and age sub-groups was determined using one-way analysis of variance (ANOVA). Pearson's correlation coefficient value for plasma BNP and LVEF was done. Diagnostic value for plasma BNP for CHF was analysed with ROC curve.

\section{Discussion}

Heart failure results from the activation of multiple pathogenic pathways. BNP estimation has a role in the diagnosis of heart failure and guiding heart failure therapy. ${ }^{8}$ In the present study, the plasma concentration of B-type natriuretic peptide in patients with stable chronic heart failure and controls was estimated. While comparing the characteristics of the participants in the present study, there was a significant difference in left ventricular ejection fraction (LVEF) among the study groups. Insignificant $p$ values were obtained for smoking, alcohol intake, BMI, the presence of diabetes mellitus and hypertension between the stable CHF and the control group (Table 1).

The mean and standard deviation of serum creatinine among stable CHF patients and controls was $0.75 \pm 0.09 \mathrm{mg} / \mathrm{dL}$ and $0.65 \pm 0.08 \mathrm{mg} / \mathrm{dL}$. Their eGFR was $100.24 \pm 8.81 \mathrm{~mL} / \mathrm{min}$ and $117.31 \pm 10.34 \mathrm{~mL} / \mathrm{min}$ respectively. The levels of serum creatinine and the estimated glomerular filtration (eGFR) were within the normal limits in all the participants in the present study. This indicates that the participants included in the study had a normal renal function, thus, excluding early occult renal failure as a cause for alterations in plasma BNP level in both the study groups. The mean and standard deviation values of age among patients with stable CHF and controls were $54.49 \pm 9.38$ and $52.51 \pm 10.40$, respectively. The mean and standard deviation of the plasma BNP concentration in patients with CHF was $60.46 \pm 16.13 \mathrm{pg} / \mathrm{mL}$, while in controls it was $20.94 \pm 5.81 \mathrm{pg} / \mathrm{mL}$ which were statistically significant. A similar result was also obtained by Tsutamoto et al. ${ }^{9}$

According to the European Society of Cardiology (2012 guidelines), the concentration of BNP $\geq 100 \mathrm{pg} / \mathrm{mL}$ is required for the diagnosis of $\mathrm{CHF}^{10}$ However, in our study in stable CHF patients, it was lower than the above-prescribed cut-off because BNP levels reduce with adequate treatment. ${ }^{11}$ Thus, BNP aids in guiding adequacy of drug therapy in CHF patients. In 2013, the American College of Cardiology Foundation (ACCF)/American Heart Association (AHA) HF guidelines have recommended the use of BNP for guiding chronic HF management (level of evidence: B). ${ }^{12}$ More recently, several meta-analyses have suggested that Natriuretic Peptide-guided therapy strategies could be associated with a reduction in all-cause mortality in CHF patients less than 75 years. ${ }^{13-15}$ However, the 2017 update guideline task force makes no recommendation regarding the use of BNP testing to guide HF therapy. ${ }^{16}$

As in Table 2, significant differences in plasma BNP concentrations were also observed between stable $\mathrm{CHF}$ patients and controls when they were classified into five sub-groups based on their age $\left(p=0.001^{*}\right)$. In addition, an increase in the concentration of plasma BNP with advancing age was observed in both stable CHF patients $(p=0.03)$ and in control $(p=0.001)$ groups. Studies by Laura, ${ }^{8}$ Braunwald ${ }^{17}$ Redfield ${ }^{18}$ and Wang et al. ${ }^{19}$ also observed a moderate increase in the levels of circulating BNP with advancing age. A study by Nishikimi in 2013 showed that total BNP levels increased with aging and the possibility could be an increased cardiac muscle mass together with a reduction in the normal renal clearance of BNP during aging. ${ }^{20}$

Table 1: Characteristics of patients in the study population

\begin{tabular}{llll}
\hline Variable & Stable CHF patients $(\mathrm{n}=55)$ & Control $(\mathrm{n}=35)$ & $p$ value \\
\hline Smoking & $27(49 \%)$ & $11(31.4 \%)$ & 0.829 \\
Alcohol intake & $22(40 \%)$ & $10(33.3 \%)$ & 0.992 \\
Presence of diabetes mellitus & $18(32.7 \%)$ & $5(14.3 \%)$ & 0.051 \\
Presence of hypertension & $23(41.8 \%)$ & $16(45.7 \%)$ & 0.716 \\
BMI & $27.19 \pm 2.56$ & $26.02 \pm 2.44$ & 0.254 \\
LVEF $(\%)$ & $35.51 \pm 5.88$ & $71.23 \pm 4.61$ & $<0.0001^{\mathrm{b}}$ \\
Plasma BNP $(\mathrm{pg} / \mathrm{mL})$ & $60.46 \pm 16.13$ & $20.94 \pm 5.81$ & $0.001^{\mathrm{a}}$ \\
\hline
\end{tabular}

${ }^{\mathrm{a}} p<0.001 ;{ }^{\mathrm{b}} p<0.0001$ 
Plasma B-type Natriuretic Peptide Levels in Stable Heart Failure Patients

Table 2: Concentration of BNP in case and controls in age sub-groups

\begin{tabular}{|c|c|c|c|c|c|c|c|}
\hline \multirow[b]{3}{*}{ Age (in years) } & \multicolumn{6}{|c|}{ Plasma BNP $(p g / m L)$} & \multirow[b]{3}{*}{ Independent t-test } \\
\hline & \multicolumn{3}{|c|}{ Stable CHF patients } & \multicolumn{3}{|c|}{ Controls } & \\
\hline & Mean & \multicolumn{2}{|l|}{$S D$} & \multicolumn{2}{|l|}{ Mean } & $S D$ & \\
\hline$<40$ & 46.32 & \multicolumn{2}{|l|}{7.69} & \multicolumn{2}{|l|}{12.95} & 2.30 & $\mathrm{t}=10.18 \mathrm{p}=0.001^{\mathrm{a}}$ \\
\hline $41-50$ & 54.77 & \multicolumn{2}{|l|}{15.33} & 19.19 & & 3.66 & $\mathrm{t}=8.45 \mathrm{p}=0.001^{\mathrm{a}}$ \\
\hline $51-60$ & 64.95 & \multicolumn{2}{|l|}{14.77} & 23.30 & & 4.76 & $\mathrm{t}=6.14 \mathrm{p}=0.001^{\mathrm{a}}$ \\
\hline $61-70$ & 64.99 & \multicolumn{2}{|l|}{19.84} & 26.66 & & 1.63 & $\mathrm{t}=5.77 \mathrm{p}=0.001^{\mathrm{a}}$ \\
\hline$>70$ & 70.67 & \multicolumn{2}{|l|}{7.66} & 30.20 & & 0.0 & $\mathrm{t}=4.57 \mathrm{p}=0.001^{\mathrm{a}}$ \\
\hline (ANOVA) & \multicolumn{3}{|c|}{$F=2.87 p=0.03$} & \multicolumn{3}{|c|}{$\mathrm{F}=20.02 \mathrm{p}=0.001^{\mathrm{a}}$} & \\
\hline \multicolumn{8}{|l|}{${ }^{\mathrm{a}} \mathrm{p}<0.001$} \\
\hline \multicolumn{8}{|c|}{ Table 3: Comparison of plasma BNP levels in male and female } \\
\hline & & \multicolumn{5}{|c|}{ Gender } & \\
\hline & & \multicolumn{3}{|c|}{ Male } & \multicolumn{2}{|c|}{ Female } & \\
\hline Analyte & Group & Mean & $S D$ & & Mean & $S D$ & Independent t-test \\
\hline \multirow[t]{2}{*}{ Plasma BNP (pg/mL) } & $\begin{array}{l}\text { Stable CHF } \\
\text { patients }\end{array}$ & 63.12 & 16.79 & & 53.98 & 12.65 & $\mathrm{t}=1.95 p=0.06$ \\
\hline & Control & 20.77 & 5.95 & & 21.28 & 5.75 & $\mathrm{t}=0.24 p=0.08$ \\
\hline
\end{tabular}

Table 4: Comparison of plasma BNP values in sub-groups of LVEF in case and controls

\begin{tabular}{lllll}
\hline Study population & LVEF $(\%)$ & No of participants & Mean and SD BNP $(\mathrm{pg} / \mathrm{mL})$ & $\mathrm{p}$ value \\
\hline \multirow{3}{*}{ Stable CHF patients } & $25-30$ & 18 & $60.53 \pm 15.99$ & $59.21 \pm 16.30$ \\
& $31-35$ & 12 & $64.33 \pm 19.11$ & 0.679 \\
& $36-40$ & 15 & $56.00 \pm 11.68$ & $27.05 \pm 2.39$ \\
Controls & $41-45$ & 10 & $20.61 \pm 3.97$ & 0.003 \\
& $60-65$ & 6 & $20.56 \pm 6.02$ & $16.22 \pm 5.27$ \\
\hline
\end{tabular}

Redfield et al. reported higher plasma BNP levels in healthy women than in men. ${ }^{18}$ Nishikimi ${ }^{20}$ in his study analyzed the effects of gender on BNP and found that females had higher BNP levels and opined that further studies are necessary to elucidate the mechanism of increased BNP levels in females. However, in our study, the levels of BNP did not vary significantly with gender in both the groups (Table 3).

Left ventricular ejection fraction (LVEF) was classified into subgroups and BNP concentration in each sub-group was analyzed (Table 4). An increase in LVEF caused a significant decrease in plasma BNP levels in the control group $(p=0.003)$. However, it was not significant in stable CHF patients $(p=0.679)$. The Pearson's correlation coefficient value for plasma BNP and LVEF in the study population showed a strong negative linear correlation with $r=-0.798$. Veena $V$ et al. in 2016 reported a strong negative correlation between BNP levels and LVEF\% in heart failure with reduced ejection fraction ${ }^{21}$.

Graph 1 shows the ROC curve which was plotted according to the data of 55 CHF patients and 35 controls. When the cut-off level of plasma BNP was higher than $30.2 \mathrm{pg} / \mathrm{mL}$, the sensitivity to predict CHF was $100 \%$, and the specificity was $100 \%$. AUC was 1.00 (0.96-1.00) for BNP. Hence, plasma BNP is sensitive and specific for identifying stable heart failure.

\section{LiMITATIONS OF THE STUDY}

The present study was done in a short duration of one year period involving a small number of participants. Echocardiography was done by a different cardiologist on different patients; hence there

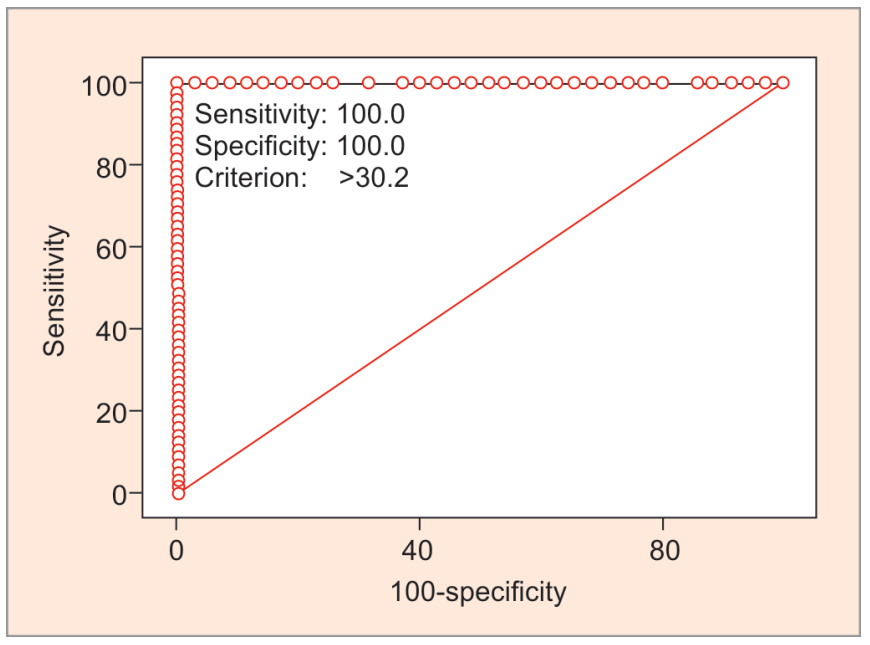

Graph 1: Analysis of the diagnostic value of plasma BNP for CHF with ROC curve

is a possibility of subjective variation while determining the left ventricular ejection fraction. Clinical examination and previous records of hemoglobin $>10 \mathrm{~g} / \mathrm{dL}$ were used to include participants in the study rather than objectively estimating hemoglobin to exclude anemia in the participants. Periodic assessment of plasma BNP at various time intervals in stable patients was not done in the present study. 


\section{Conclusion}

In conclusion, plasma BNP was significantly higher in patients with stable chronic heart failure than in the controls. The concentrations of plasma BNP increased as the age of the participants increased. There was a strong negative correlation between plasma BNP levels and LVEF. A cut-off level of $30.2 \mathrm{pg} / \mathrm{mL}$ for plasma BNP had a $100 \%$ sensitivity and specificity to predict CHF. Plasma BNP as a biomarker will help in identifying stable CHF patients who are asymptomatic, on their adequacy of treatment.

\section{ACKnowledgments}

Authors express their warm regards to all the participants of this study for their valuable time, co-operation and samples provided by them. They are grateful to Dr Dhanadapani, Institute of Cardiology, Rajiv Gandhi Government General Hospital, Chennai for permitting the corresponding author to attend the cardiology outpatient department and to carry out the project. Their colleagues for helping them in preparing a proforma for the project and during sampling, the Lab Supervisors of Institute of Biochemistry for their support and guidance while sample processing and Dr M Subbiah, Statistician for helping them with the analysis of the data.

\section{References}

1. Dickstein K, Cohen-Solal A, Filippatos G, et al. ESC guidelines for the diagnosis and treatment of acute and chronic heart failure 2008: the Task Force for the diagnosis and treatment of acute and chronic heart failure 2008 of the European Society of Cardiology. Eur J Heart Fail 2008;10: 933-989.

2. Ambrosy AP, Fonarow GC, Butler J, et al. The Global Health and Economic Burden of Hospitalizations for Heart Failure. Lessons Learned From Hospitalized Heart Failure Registries. J Am Coll Cardiol 2014; 63:1123-1133.

3. Braunwald E. Heart failure. JACC Heart Fail 2013;1:1-20.

4. Schellenberger U, O'Rear J, Guzzetta A, et al. The precursor to B-type natriuretic peptide is an O-linked glycoprotein. Arch. Biochem. Biophys. 2006;451(2):160-166.

5. Battaglia M, Pewsner D, Juni P, et al. Accuracy of B-type natriuretic peptide tests to exclude congestive heart failure: systematic review of test accuracy studies. Arch Intern Med. 2006 May 22;166(10): 1073-1080.

6. Austin WJ, Bhalla V, Hernandez-Arce I, et al. Correlation and prognostic utility of B-type natriuretic peptide and its amino-terminal fragment in patients with chronic kidney disease. 2006, Am. J. Clin. Pathol. 126(4):506-512.

7. Kim HN, Januzzi Jr JL. Natriuretic peptide testing in Heart failure, Circulation, 2011;123:2015-2019.
8. Leto L, Testa M, Feola M. Correlation between B-Type Natriuretic Peptide and Functional/Cognitive Parameters in Discharged Congestive Heart Failure Patients. International Journal of Endocrinology, 2015; pp 7.

9. Tsutamoto TA, Wada A, Maeda K, et al. Plasma brain natriuretic peptide level as a biochemical marker of morbidity and mortality in patients with asymptomatic or minimally symptomatic left ventricular dysfunction: comparison with plasma angiotensin II and endothelin. Eur Heart J 1999;20:1799-1807.

10. John J.V. McMurray et al, ESC Guidelines for the diagnosis and treatment of acute and chronic heart failure 2012,European Heart Journal 2012;33:1787-1847.

11. ChowSL, Maisel AS, Anand I, et al. Role of Biomarkers for the Prevention, Assessment, and Management of Heart Failure: A Scientific Statement from the American Heart Association. Circulation 2017;Apr 26:[Epub ahead of print].

12. Yancy CW, Jessup M, Bozkurt B, et al. 2013 ACCF/AHA guideline for the management of heart failure: a report of the American College of Cardiology Foundation/American Heart Association Task Force on Practice Guidelines. J Am Coll Cardiol 2013;62:e147-239.

13. Xin W, Lin Z, Mi S, Does B-type natriuretic peptide-guided therapy improve outcomes in patients with chronic heart failure? A systematic review and meta-analysis of randomized controlled trials, Heart Fail Rev 2015;20:69-80.

14. De Vecchis R, Esposito C, Di Biase G, et al., B-type natriuretic peptideguided versus symptom-guided therapy in outpatients with chronic heart failure: a systematic review with meta-analysis, J Cardiovasc Med 2014;15:122-134.

15. Savarese G, Trimarco B, Dellegrottaglie S, et al., Natriuretic peptideguided therapy in chronic heart failure: a meta-analysis of 2,686 patients in 12 randomized trials, PLoS One 2013;8:e58287.

16. Yancy, CW, Jessup M, Bozkurt B, et al. 2017 ACC/AHA/HFSA Focused Update of the 2013 ACCF/AHA Guideline for the Management of Heart Failure: A Report of the American College of Cardiology/American Heart Association Task Force on Clinical Practice Guidelines and the Heart Failure Society of America 2017 July 11;136(2):2.

17. Biomarkers in heart failure. N Engl J Med 2008;358:2148-2159.

18. Redfield MM RR, Jaoobsen SJ, et al. Plasma brain natriuretic peptide concentration: impact of age and gender. J Am Coll Cardiol. 2002;40:976-982.

19. Wang TJ, Larson MG, Levy $D$, et al. Impact of age and sex on plasma natriuretic peptide levels in healthy adults, American Journal of Cardiology, 2002;90(3):254-258.

20. Nishikimi T, Okamoto H, Nakamura M, et al. Direct Immunochemiluminescent Assay for proBNP and Total BNP in Human Plasma proBNP and Total BNP Levels in Normal and Heart Failure. PLoS ONE 2013;8(1):e53233.

21. Veena V, Ganesh M, Santhi S. Correlation between brain-type natriuretic peptide (BNP) levels \& left ventricular ejection fraction (LVEF) in heart failure. International Journal of Clinical Biochemistry and Research, 2016;3(4):461-465. 